\title{
A ÚLTIMA AULA DE ANTONIO BARROS DE CASTRO*1
}

\author{
Eduardo F. Bastian ${ }^{a}$ \\ Fabio de Silos Sá Earp ${ }^{b}$
}

\begin{abstract}
RESUMO: Seis dias antes de seu falecimento, o professor Antonio Barros de Castro proferiu a primeira aula de seu curso na pós-graduação do Instituto de Economia da UFRJ, a qual seria a última de sua vida. Nessa aula, apresentou sua atual agenda de pesquisa, que procurava articular os temas em que concentrava seu estudo e reflexão atuais - a ascensão da China no cenário mundial, a crise financeira do Ocidente e os desafios da economia brasileira diante deste novo mundo que está emergindo Apresentamos aqui uma síntese organizada das notas que tomamos daquela aula, acrescidas de algumas observações que contribuem para contextualizá-las no conjunto das preocupações de Castro.
\end{abstract}

PALAVRAS-CHAVE: Ascensão chinesa; crise financeira; desafios brasileiros.

CLASSIFICAÇÃO JEL: O10; O25.

\section{ANTONIO BARROS DE CASTRO’S LAST LECTURE}

ABSTRACT: Six days before his death, Professor Antonio Barros de Castro gave the first lecture of his graduate course at the Institute of Economics of the Federal University of Rio de Janeiro, which happened to be the last lecture of his life. He presented his current research agenda, whose main subjects were China's rise in the world economy, the financial crisis of the West and the challenges Brazil has been facing in this new emerging world. This article is intended to present a synthesis of the notes we took from China's last lecture, in addition to some personal comments that may help contextualise his ideas and current research agenda.

KEYWORDS: China's rise; financial crisis; Brazilian challenges.

\footnotetext{
* Artigo recebido em 20/05/2012 e aprovado em 12/07/2012.

${ }^{1}$ Os autores agradecem os comentários e sugestões de Ana Célia Castro e Lavínia Barros de Castro.

a Doutor em Economia e professor adjunto do Instituto de Economia da Universidade Federal Rio de Janeiro (UFRJ). Contato: eduardobastian@ie.ufrj.br.

${ }^{\mathrm{b}}$ Doutor em Economia e professor associado do Instituto de Economia da UFRJ. Contato: fsaearp@ie.ufrj.br.
} 


\section{APRESENTAÇÃO}

Este é um artigo que não gostaríamos de ter escrito. Quis o destino, porém, que na manhã daquela segunda-feira, 15 de agosto de 2011, o Castro estivesse dando a primeira aula de um curso que jamais viria a continuar. A sala estava superlotada, com grande número de alunos não matriculados, como costumava acontecer nos cursos que oferecia, sobretudo depois de sua aposentadoria e sua reintegração como Professor Emérito do Instituto de Economia da UFRJ (IE-UFRJ). O tema do curso era os dilemas do Brasil contemporâneo e os desafios associados à ascensão da China, tópicos que começou a abordar já nessa primeira aula, a qual reproduziremos aqui, na medida em que nossas anotações e nossa memória nos permitam².

Observe também o leitor que os que aqui escrevem pertencem a gerações diferentes e que tiveram distintas experiências com Castro. Por isso, em alguns casos, têm percepções pessoais, não compartilhadas, mas que eventualmente podem ser úteis para o leitor. Assim, quando algum comentário for de caráter individual de um dos autores, o apresentaremos em itálico e devidamente identificado pelas iniciais do autor. Por sinal, optamos por introduzir dois curtos depoimentos pessoais, antes de entrarmos no tema da aula propriamente.

Membro de uma geração de grandes professores, Castro está entre os poucos que conseguiram conciliar erudição, criatividade e consistência. Rejeitava veementemente as verdades fáceis, mas renegava também a criatividade voluntarista. Seu profissionalismo se manifestava tanto no absoluto rigor conceitual com que orientava seus alunos de doutorado e mestrado, como também no esmero e capricho com que preparava seus artigos e suas aulas. Em sala de aula, tinha um dom para transmitir o conteúdo que fazia os temas mais enfadonhos tornarem-se instigantes. O curioso é que, muitas vezes, ele se desculpava antes do começo da aula por não ter preparado direito o material que iria apresentar, o que desconcertava os alunos, pois, ao final da aula, era impossível acreditar que o conteúdo não fora preparado minuciosamente. O que acontecia é que Castro ficava muito incomodado se não tivesse refletido profundamente sobre cada ponto, de modo que, se houvesse alguma parte que ele considerasse não estar suficientemente bem tratada, isto bastaria para ele considerar o conteúdo da aula insatisfatório. (E.F.B.) Os quatro cursos ministrados por Antonio Barros de Castro se inscrevem entre os mais brilhantes que assisti ao longo de três décadas e meia de vida acadêmica. Castro era um

\footnotetext{
${ }^{2}$ A aula retoma vários pontos que Castro já havia discutido em outra aula ministrada no dia 08 de julho de 2011, por ocasião do encerramento do curso Seminários de Economia Brasileira, oferecido pelo Programa de Pós-Graduação em Economia (PPGE) do IE-UFRJ, ministrado pelos autores e pelo professor André Modenesi. Como a aula de julho foi mais longa, Castro apresentou com mais detalhes alguns pontos que reapareceram em 15 de agosto. Desta forma, resolvemos adicionar ao presente texto algumas observações feitas na aula de julho. Todavia, para não interferir no conteúdo daquela que foi efetivamente a última aula, informaremos o leitor sempre que utilizarmos observações referentes à aula de 08 de julho.
} 
artesão que não repetia aulas, mas burilava cada uma pelo maior tempo possível, como se não quisesse deixar rastro do que apresentara sob o mesmo título no período anterior, frequentemente com recomendações bibliográficas distintas. Dava suas aulas sentado, falando pausadamente, consultando anotações, sem usar o quadro negro; jamais permitia que o brilho da retórica turvasse a profundidade do raciocínio. Em alguns pontos não escondia o prazer que sentia pelas conclusões que finalmente podia apresentar aos alunos. Quando, uma semana antes do início desse semestre letivo, fui pedir sua autorização para assistir a esta disciplina, solicitou que comunicasse aos alunos interessados que chegassem rigorosamente no horário, pois considerava que os minutos iniciais seriam essenciais para a compreensão do que iria apresentar. (F.S.E.)

\section{ASCENSÃO CHINESA, CRISE INTERNACIONAL E DESAFIOS DA ECONOMIA BRASILEIRA: A ÚLTIMA AULA DE ANTONIO BARROS DE CASTRO}

A última aula de Castro foi a primeira do que seria seu novo curso na pós-graduação do IE-UFRJ. Em vista disso, foi uma aula de apresentação em que ele procurou contextualizar as questões que pretendia tratar em curso e, em linhas gerais, expor a abordagem que utilizaria para lidar com a problemática. Sempre atento aos desafios do futuro, Castro discutiu nesta aula algumas tendências da economia mundial e as restrições e oportunidades que este novo contexto poderá oferecer ao Brasil.

$\mathrm{Na}$ visão de Castro, os próximos 10 anos estarão condicionados por três grandes questões: 1) a ascensão chinesa; 2) a crise internacional; 3) a questão ecológica. Aparentemente, todos estes elementos são de ruptura, mas ainda é preciso entender melhor o que será ruptura e onde haverá continuidade. De todo modo, trata-se, em princípio, de três elementos estruturantes que, querendo ou não, empresas e governos terão que enfrentar. Igualmente importante, nenhuma dessas questões foi prevista, o que coloca em cheque a maneira como os economistas analisam o mundo.

O curso estaria concentrado nas duas primeiras questões, ficando o terceiro item de fora. A reflexão de Castro sobre tais questões discorreria em torno dos seguintes tópicos: o desafio da ascensão chinesa à teoria convencional; as transformações que vem ocorrendo na economia mundial, com destaque para o crescente papel da China; e, obviamente, os desafios e as oportunidades da economia brasileira nesta economia mundial sinocêntrica.

Do ponto de vista do desafio teórico, Castro observou que as características absolutamente singulares do desenvolvimento chinês eram desconcertantes para os economistas convencionais, uma vez que a teoria neoclássica tem como imagem a Física, e a Física - tal como a Ciência em geral - se pretende única. A pretensa universalização na economia fez com que, nas últimas décadas, os estudos de casos nacionais fossem em larga escala abandonados e dessem lugar a estudos cross-section que pegavam dados 
de 60 ou 70 países sem respeitar as especificidades dos países incluídos na amostra ${ }^{3}$. Nesse contexto, o caráter único e específico da ascensão chinesa estava, portanto, despertando novamente a atenção para a importância dos estudos de caso de experiências nacionais 4 . E frisou: "A China é única, específica; ou se estuda a China ou não se fala sobre a China".

Quanto às transformações na economia mundial, Castro destacou que o momento atual seria a terceira fase de rupturas que ele, pessoalmente, estaria vivenciando. A primeira ocorreu nos seus tempos de estudante, quando da reconstrução do mundo após a Segunda Guerra Mundial. A segunda aconteceu nos anos 1980, como resultado do advento daquilo que, em termos polanyianos, poderia ser chamado de fundamentalismo de mercado ${ }^{5}$. A fase atual, por sua vez, consiste em um processo de mudança envolvendo a crise dos países desenvolvidos, a ascensão dos países emergentes e, last but not least, a ascensão chinesa e os seus desafios.

Com relação à crise dos países desenvolvidos, o aspecto principal é a crise financeira internacional iniciada em 2008. Castro salientou que a solução adotada em muitos países seguiu a visão keynesiana, ou seja, a ideia que, aumentando a demanda, o emprego e a renda voltariam a crescer. O problema foi que o desemprego não cedeu, o que criou a sensação de que haveria uma nova rodada de crise. Além disso, após o aumento do endividamento público em função das políticas expansionistas para tentar conter a primeira fase da crise, a possibilidade de usar hoje o remédio keynesiano ficou muito mais limitada. Dessa forma, a crise dos desenvolvidos pode ainda ser longa, talvez não tão longa como aquela experimentada pelos países da América Latina nos anos 1980, mas, ainda assim, duradoura.

A ascensão das economias emergentes (a "emergência dos emergentes", como frisou, com um leve sorriso) está, por sua vez, fortemente associada à ascensão da China. Conforme explicitado por Castro em outro momento a China estaria emprestando ao mundo algumas de suas características ${ }^{6}$. Sendo a China um país com oferta limitada de recursos naturais, a ascensão chinesa passou a impor ao mundo a escassez destes recursos, em um processo que traz como consequência o aumento dos preços

\footnotetext{
${ }^{3} \mathrm{O}$ problema da universalização é que, ao tratar de maneira quase indiscriminada os dados, acaba-se por chegar à conclusão de que países muito distintos devem adotar o mesmo tipo de política. Nas palavras de Castro, "tenta-se estender para a China aquilo que vale, por exemplo, para a Jamaica".

${ }^{4}$ Castro fez a ressalva de que este tipo de estudo nunca foi abandonado no IE-UFRJ. Cabe destacar também que, nos anos 1980 e início dos anos 1990, houve, fora da ortodoxia, alguns estudos importantes de experiências nacionais de desenvolvimento, como, por exemplo, os livros de Chalmers Johnson sobre o Japão, Alice Amsden sobre a Coréia do Sul e Robert Wade sobre Taiwan. (E.F.B.)

${ }^{5}$ Neste ponto apontou a importância de entender as diferentes combinações entre a área de intervenção estatal e aquela deixada ao autoajuste do mercado. No caso chinês, citou que as grandes empresas estão sob a tutela do Estado, enquanto as pequenas foram entregues à iniciativa privada e flutuam ao sabor do mercado.

${ }^{6}$ Todas as informações deste e do próximo parágrafos foram apresentadas na aula de 08 de julho.
} 
das commodities. Por outro lado, os baixos custos de mão de obra permitiram que os chineses invadissem o mundo com manufaturas muito mais baratas. Ressaltou que já não há mais na China a situação de oferta ilimitada de mão de obra, de modo que, ainda que os ganhos de produtividade continuem a acontecer, os salários agora passaram a crescer. Ainda assim, este movimento não é suficiente para retirar a competitividade chinesa ${ }^{7}$. Com isso, este duplo movimento engendrado pela emergência daquela economia - leia-se a forte demanda por commodities e a oferta de produtos manufaturados com preços baixos - mudou radicalmente as relações de troca entre manufaturas e recursos naturais, estabelecendo um quadro inverso ao traçado no modelo de Hans Singer ${ }^{8}$.

Neste novo mundo, Castro argumentou que os países desenvolvidos passaram a sofrer com a concorrência chinesa nos manufaturados ${ }^{9}$. até porque faz tempo que a China também já consegue competir em ramos em que a tecnologia é fundamental. Do ponto de vista dos emergentes exportadores de recursos naturais, o traço mais marcante dessa nova dinâmica é a apreciação das taxas de câmbio, as altas taxas de crescimento e, em muitos casos, a explosão da chamada classe $\mathrm{C}^{10}$.

Dessa forma, chega-se, por fim, aos desafios que o crescimento chinês impõe ao Brasil. Segundo Castro, o Brasil preparou-se para crescer e cresce de forma firme desde 2004, ainda que alguns analistas tenham a tendência de minimizar o processo como uma mera saída da estagnação. Hoje, a presidenta Dilma Rousseff estaria combinando as contribuições dos governos Lula (crescimento com inclusão social) e Fernando Henrique Cardoso (estabilidade), acrescentando as políticas públicas de investimento. Ademais, o país detém um conjunto de empresas modernas - fruto de um bem sucedido esforço de modernização durante a segunda metade dos anos 1990 - e manteve os principais bancos estatais ${ }^{11}$.

Todavia, Castro encerrou a aula demonstrando certa reticência em relação à forma como a política industrial vem sendo conduzida no Brasil. Para ele, uma política industrial

\footnotetext{
${ }^{7}$ Castro chamou a atenção para o fato que não é em todos os produtos manufaturados que os chineses têm vantagens. Os automóveis seriam um caso em que os chineses não são tão competitivos, ainda que já estejam avançando neste setor.

${ }^{8}$ Conforme explicado por Castro, o modelo de Hans Singer estabelecia que os oligopólios e os sindicatos sustentavam os preços dos setores industriais, enquanto que, no caso dos bens primários, os preços caíam. Neste contexto, os países desenvolvidos tinham uma dupla vantagem, pois produziam produtos cujos preços não caíam e compravam produtos cujos preços caíam.

${ }^{9}$ Entendemos que este quadro também vale para os emergentes que possuem base industrial.

${ }^{10}$ Castro afirmou que a ascensão da classe C estaria também acontecendo na África. Ele retirou esta informação de um relatório do African Development Bank.

${ }^{11}$ Castro não chegou a desenvolver este ponto acerca da importância dos bancos estatais. Acreditamos que ele tinha em mente a atuação que estes bancos tiveram na rápida recuperação do Brasil quando da eclosão da crise financeira internacional em 2008-2009.
} 
adequada deve focar no novo, ou seja, nos desafios impostos pela tríplice problemática antes destacada. Na visão dele, a política industrial implícita dada pela China é a do reposicionamento, o que, por sinal, é o que as empresas estão fazendo, mas não o que está contemplado na política industrial que, até aquela data, vinha sendo colocada em prática no Brasil ${ }^{12}$.

\section{EPÍLOGO}

A primeira aula terminou com a apresentação desse cardápio que degustaríamos lentamente ao longo do segundo semestre de 2011. Enunciava a discussão de um conjunto de questões que incluíam certezas, dúvidas, desconfianças e perplexidades do velho professor. Pediu-nos que lêssemos três textos para o próximo encontro: o de Fernando Cardim de Carvalho sobre Keynes e a reforma da ordem capitalista, publicado em 2006 no Journal of Post-Keynesian Economics (JPKE); os capítulos 1, 3 e 10 do The Return of Depression Economics (o original, não a tradução brasileira), de Paul Krugman, e o clássico de Karl Polanyi, A Grande Transformação.

Não tivemos a oportunidade de saber como Castro articularia esses autores. $\mathrm{Na}$ segunda feira seguinte não houve aula; na subseqüente, no mesmo horário, nos encontramos no velório, chocados diante do ocorrido. Sobre todos pesava o sentimento de orfandade, diante da ausência desse pensador que, como Schumpeter, visitava todas as disciplinas sem perder o foco da economia, ainda que dificilmente se enquadrasse em qualquer escola de pensamento, alguém que foi certa vez definido por seu amigo Jáder de Andrade como "um famoso e brilhante economista, que não cabe em nenhuma camisa" (Castro, 2011, p. 11).

Ao relermos agora as notas de sua última aula, não conseguimos evitar a sensação de estarmos diante dos esboços de um quadro inacabado de um grande pintor ou um romance incompleto de um importante escritor. Assim, essas notas resgatam os temas

\footnotetext{
${ }^{12} \mathrm{Na}$ aula de 08 de julho, Castro desenvolveu mais o tema. Nesta aula, ele argumentou que o Brasil não entrou ainda na órbita chinesa em função do seu mercado interno, mas já começa a entrar. Por exemplo, produtos que o Brasil vende para a China - como minério de ferro, soja e celulose - respondem por mais de $40 \%$ das exportações brasileiras hoje. Com isso, o crescimento brasileiro aproxima-se do tipo de crescimento de Angola, Argentina e Peru. No que tange à política industrial, entendia que adotar uma posição puramente defensiva diante da China seria um grande equívoco. Dizia: "Perderemos batalha após batalha". Ainda assim, acreditava que o Brasil poderia permanecer como um país de bom nível industrial. Seus últimos escritos atestam que, de fato, ele não estava pessimista e enxergava uma série de oportunidades para o país. No caso, o fundamental era ter uma estratégia condizente com os desafios associados a este novo mundo que está emergindo. Para exemplos de trabalhos de Castro discutindo o caso chinês e os desafios brasileiros, ver Castro (2008a) e Castro (2008b). Para uma coletânea de artigos de Castro e uma das suas últimas entrevistas, ver Castro e Castro (2011). Para uma discussão da trajetória intelectual de Castro, culminando com as suas discussões mais recentes sobre a China e política industrial, ver Prado e Bastian (2011).
} 
com os quais Castro estava trabalhando e fornecem pistas sobre o encaminhamento que ele pretendia dar. Estamos convictos de que os jovens economistas aproveitarão essas pistas e darão continuidade. Se as notas de aula de Castro são como um romance que ficou aberto, estamos seguros de que este não é o ponto final ${ }^{13}$.

\section{REFERÊNCIAS BIBLIOGRÁFICAS}

CASTRO, A. C.; CASTRO, L. B. (Orgs.). Antonio Barros de Castro: o inconformista - homenagem do Ipea ao mestre. Brasília: IPEA, 2011.

CASTRO, A. C. Introdução. In: CASTRO, A. C.; CASTRO, L. B. (Orgs.). Antonio Barros de Castro: $o$ inconformista - homenagem do IPEA ao mestre. Brasília: IPEA, 2011.

CASTRO, A. B. No Espelho da China. Digesto Econômico, São Paulo, n. 447, p. 24-35, 2008 a.

CASTRO, A. B. From semi-stagnation to growth in a sino-centric market. Revista de Economia Política, São Paulo, v. 28, p. 15-45, 2008 b.

PRADO, L. C.; BASTIAN, E. F. Um economista no labirinto: um obituário de Antonio Barros de Castro. Dados - Revista de Ciências Sociais, Rio de Janeiro, v. 54, n. 3, p. 243-258, 2011.

${ }^{13}$ Aqui a referência é explícita ao poema Este Quarto, de Mário Quintana, no trecho "e a própria vida, eu a deixei no meio / como um romance que ficasse aberto." 